\title{
Deuterium-depleted water stimulates GLUT4 translocation in the presence of insulin, which leads to decreased blood glucose concentration
}

\author{
Miklós Molnár ${ }^{1} \cdot$ Katalin Horváth $^{1} \cdot$ Tamás Dankó ${ }^{2}$ Ildikó Somlyai ${ }^{2} \cdot$ Beáta Zs. Kovács ${ }^{2} \cdot$ Gábor Somlyai $^{2}$
}

Received: 10 December 2020 / Accepted: 19 July 2021 / Published online: 12 September 2021

(c) The Author(s) 2021

\begin{abstract}
Deuterium (D) is a stable isotope of hydrogen $(\mathrm{H})$ with a mass number of 2. It is present in natural waters in the form of HDO, at a concentration of $16.8 \mathrm{mmol} / \mathrm{L}$, equivalent to $150 \mathrm{ppm}$. In a phase II clinical study, deuterium depletion reduced fasting glucose concentration and insulin resistance. In this study, we tested the effect of subnormal D-concentration on glucose metabolism in a streptozotocin (STZ)-induced diabetic rat model. Animals were randomly distributed into nine groups to test the effect of $\mathrm{D}_{2} \mathrm{O}$ (in a range of $25-150 \mathrm{ppm}$ ) on glucose metabolism in diabetic animals with or without insulin treatment. Serum glucose, fructose amine-, HbA1c, insulin and urine glucose levels were monitored, respectively. After the 8-week treatment, membrane-associated GLUT4 fractions from the soleus muscle were estimated by Western blot technique. Our results indicate that, in the presence of insulin, deuterium depletion markedly reduced serum levels of glucose, -fructose amine, and $-\mathrm{HbA1c}$, in a dose-dependent manner. The optimal concentration of deuterium was between 125 and $140 \mathrm{ppm}$. After a 4-week period of deuterium depletion, the highest membrane-associated GLUT4 content was detected at $125 \mathrm{ppm}$. These data suggest that deuterium depletion dose-dependently enhances the effect of insulin on GLUT4 translocation and potentiates glucose uptake in diabetic rats, which explains the lower serum glucose, -fructose amine, and -HbAlc concentrations. Based on our experimental data, deuterium-depleted water could be used to treat patients with metabolic syndrome (MS) by increasing insulin sensitivity. These experiments indicate that naturally occurring deuterium has an impact on metabolic regulations.
\end{abstract}

Keywords Deuterium (D) · Deuterium-depleted water (DDW) · Deuterium depletion · Diabetes mellitus (DM) · GLUT-4 translocation

Gábor Somlyai

gsomlyai@hyd.hu

Miklós Molnár

molnar.miklos_g@med.semmelweis-univ.hu

Katalin Horváth

horvkat@gmail.com

Tamás Dankó

dantam2004@gmail.com

Ildikó Somlyai

isomlyai@hyd.hu

Beáta Zs. Kovács

bzskovacs@hyd.hu

1 Institute of Pathophysiology, Faculty of Medicine, Semmelweis University, Budapest, Hungary

2 HYD LLC for Cancer Research and Drug Development, Villányi út 97, 1118 Budapest, Hungary

\section{Introduction}

Deuterium (D), a naturally occurring stable isotope of hydrogen, is present in natural surface waters predominantly in the form of HDO and at a concentration of approximately $16.8 \mathrm{mmol} / \mathrm{L}$. The two isotopes, hydrogen $\left({ }^{1} \mathrm{H}\right)$ and deuterium $\left({ }^{2} \mathrm{H}\right)$ have the largest mass difference among stable isotopes of the same element, resulting in significant differences in both chemical and physical properties [1-3].

The effect of $\mathrm{D}$ at elevated concentrations has been investigated thoroughly in various biological systems [4, 5], but these studies ignored the significance of natural D-concentrations.

In nature, the deuterium to hydrogen $(\mathrm{D} / \mathrm{H})$ ratio is approx. 1:6600; the natural abundance of $\mathrm{D}$ is about $150 \mathrm{ppm}(0.015$ atom\%) [2]. Global concentration of D ranges between 120 and $160 \mathrm{ppm}$ depending on the site of 
sampling $[6,7]$ and the available data suggest that $\mathrm{D} / \mathrm{H}$ ratio is not constant in living organisms, either [8].

Deuterium in the human plasma is abundant with concentrations reaching $12-14 \mathrm{mmol} / \mathrm{L}$, in comparison with the $2.24-2.74 \mathrm{mmol} / \mathrm{L}$ concentration of calcium, $0.75-1.2 \mathrm{mmol} / \mathrm{L}$ concentration of magnesium, $5.0-5.1 \mathrm{mmol} / \mathrm{L}$ value of potassium and 3.3-6.1 mmol/L circulating concentration of glucose.

Early results showing the impact of reduced D-concentrations on living organisms were first published in 1993 [9]. Since then, numerous experimental and clinical observations have further suggested that deuterium depletion has an antimitotic effect in various tumor cells $[9,10]$. This effect is, in part, due to the alteration of $\mathrm{H}^{+}$-ATPase and $\mathrm{Na}^{+} / \mathrm{H}^{+}$antiport system [9]. Other studies have shown that deuterium-depleted water (DDW)-induced apoptosis in cancer cells, both in vitro and in vivo [10-12]. The inhibitory effect of DDW on the expression of proto-oncogenes such as c-Myc, Ha-ras and p53 has been documented, as well [13]. Complete or partial tumor regression has been established in mice xenografts with MDA-MB-231, MCF-7 human breast adenocarcinoma cell lines and PC-3 human prostate tumor cells, respectively. When laboratory animals were exposed to chemical carcinogenesis by 7,12-dimethyl-benzanthracene (DMBA), cytoplasmic myelocytomatosis oncogenes, c-Myc, Ha-ras, and p53 were up-regulated, while DDW, applied as drinking water, suppressed the expression of these oncogenes. DDW significantly inhibited proliferation of A549 human lung carcinoma cells in vitro, and H460 lung tumor xenografts in laboratory mice showed a $30 \%$ regression in growth. The anticancer effect of deuterium depletion has already been confirmed in a double-blind, randomized, 4-month-long, phase 2 clinical trial on prostate cancer, and the extended follow-up suggests that DDW delays the progression of the disease [14]. Retrospective clinical studies confirmed the anticancer effect of DDW as the consumption of DDW led to a several fold increase in the median survival time (MST) of patients with prostate, breast, lung and pancreatic cancer, respectively [14-17]. Deuterium-depleted water may be included as a non-toxic anticancer treatment modality for prevention and treatment. [18, 19].

At submolecular level, it has been shown that most of the extramitochondrial NADPH synthesis pathways are targeted by DDW. The terminal complex of mitochondrial electron transport chain (ETC) reduces molecular oxygen to deuterium-depleted metabolic water which affects gluconeogenesis as well as fatty acid oxidation. NADPH's deuterium labeling depends on carbon-specific positional glucose deuterium enrichment, as well as deuterium enrichment of the cytoplasmic and mitochondrial water pools within cells $[18,19]$.Furthermore, switching from a ketogenic to highsugar diet interferes with the deuterium-depleting action of mitochondria serving as a potential oncogenic initiator [18].
Multiple lines of evidence suggest that $\mathrm{D}_{2} \mathrm{O}$ inhibits insulin release from pancreatic islets by stabilizing the microtubular system of the $\beta$-cells or by inhibiting oxidative phosphorylation [20-22]. In addition, the intracellular $\mathrm{H}^{+}$-concentration plays a critical role in the glucose-induced, time-dependent potentiation of insulin release in pancreatic $\beta$-cells, as well [23]. Reduction in intracellular $\mathrm{pH}$ leads to the translocation of glucose transporters GLUT4 and GLUT1 to the sarcoplasma in the canine heart [24]. Based on these findings and the results confirming the key role of naturally occurring $\mathrm{D}$ in cell cycle regulation, it was logical to assume that deuterium depletion could interfere with glucose metabolism as well. Further evidence supporting this hypothesis was obtained from participants of clinical studies to verify the anticancer effect of deuterium depletion, where application of DDW in patients with cancer and diabetes mellitus (DM), resulted in significantly lower blood glucose levels [25].

Ingestion of 1.5 L DDW (104 ppm D) per day for 90 days was mostly beneficial by altering some parameters related to metabolic syndrome in patients with pre-diabetes or manifest diabetes mellitus. D content of the body had an impact on the physiological regulation in insulin-resistant patients. The fact that DDW simultaneously influenced insulin-, HDL- and glucose levels suggests that the concentration of D within the organism may have an important role in harmonizing metabolic processes. In summary, the results support the beneficial role of DDW in disorders of glucose metabolism [25]. In a phase 2 clinical study 30 volunteers with decreased glucose tolerance consumed DDW (104 ppm D) for 90 days. By the end of the trial the insulin concentration decreased in $50 \%$ of the volunteers, which correlated well with a decrease in glucose levels in the same participants. In addition, in 11 subjects glucose disposal was found to be improved significantly [25].

This study aimed to evaluate the effect of DDW on the whole-body glucose homeostasis in streptozotocin (STZ)induced diabetic rat model as well as to elucidate the possible underlying mechanism. Here we show that DDW alone did not alter the glucose uptake of diabetic rats. However, DDW dose-dependently potentiates the effect of insulin, administered in a suboptimal dose, on glucose homeostasis. This effect, at least in part, may be attributed to the increased GLUT-4 protein translocation from the cytosol to the membrane of skeletal muscle cells.

\section{Materials and methods}

\section{Animals}

A total of 96 adult male Wistar rats (Charles River, Budapest, Hungary) weighing 180-200 g were used for the 
experiments. The animals were housed in hanging wire cages maintained at $21-22{ }^{\circ} \mathrm{C}$, constant humidity, and $12 \mathrm{~h}$ light/12 h dark cycle (with lights on at 6.00 PM). Standard rat chow and water were given ad libitum.

The animal treatments were in compliance with guidelines established by the Animal Care Committee of Semmelweis University and the Hungarian Guide for the Care and Use of Laboratory Animals.

\section{Induction of diabetes}

A period of 7 days was allowed for the animals to acclimatize before any experimental manipulations were performed. Prior to STZ treatment [26, 27], all animals were placed in metabolic cages for $24 \mathrm{~h}$. Urine and $1 \mathrm{~mL}$ blood samples were collected to verify pretreatment values of the study parameters in all animals. Diabetes was induced in $12 \mathrm{~h}$ fasted rats with a single intraperitoneal injection of streptozotocin (STZ, Sigma, Budapest) $60 \mathrm{mg} / \mathrm{bw}-\mathrm{kgs}$, dissolved in $10 \mathrm{mmol}$ sodium citrate buffer ( $\mathrm{pH}: 4.5$ ) at a concentration of $90 \mathrm{mg} / \mathrm{mL}$ immediately before use. Age and weight matched control rats received an equal volume of citrate buffer only. After STZ injection, rat chow was given back immediately to prevent the development of hypoglycemia. All animals were kept under the same conditions and monitored closely for 2 weeks. To confirm the diabetic status, animals were placed again into metabolic cages for $24 \mathrm{~h}$ and urine and blood samples were collected. Only animals with polyuria, polydipsia, and plasma glucose concentrations above $15 \mathrm{mmol} / \mathrm{L}$ were considered diabetic and used in the study (Tables 1,2).

\section{Experimental design $\mathbf{A}$}

To investigate the effect of DDW on metabolic changes occur in diabetes, diabetic and control rats were divided into two main groups: half of the animals were given DDW (25 ppm D), and the other half received normal tap water (150 ppm D), both provided ad libitum. To determine whether DDW exerts its effects, at least partially, by modifying the action of insulin, diabetic rats were further divided into subgroups according to insulin treatment. The control rats did not receive insulin treatment. We did not want to achieve euglycaemia by insulin treatment, but to prevent severe acute complications only. Therefore, two different doses of insulin (Huminsulin Lilly Normal 100 I.E./mL) were used: a low dose (1 IU/300 g bw./day) to prevent ketosis and a moderate dose (2 IU/300 g bw./day) to prevent severe hyperglycaemia.

The insulin was administered subcutaneously in equal portions twice daily (8.00 AM and 6.00 PM). Treatments started at the 2nd week after STZ injection and lasted for an additional 8 weeks.

\section{Experimental design B}

To identify the most effective deuterium concentration, diabetic rats $(n=72)$ receiving a fixed low dose of insulin (1 IU/300 g bw./day) were treated with water containing different concentrations of deuterium (between 150 and $25 \mathrm{ppm}$ D). According to this protocol, animals were divided into 9 subgroups based on the deuterium content of drinking water: Group25 $(n=8) 25 \mathrm{ppm}$ D, Group75 $(n=8) 75 \mathrm{ppm} \mathrm{D,}$ Group105 $(n=8) 105$ ppm D, Group125 $(n=8) 125$ ppm D,
Table 1 Effect of deuterium content of drinking water on the metabolic parameters of nondiabetic rats in a control group
Table 2 Effect of deuterium content of drinking water on the metabolic parameters of STZ-treated rats without insulin administration

\begin{tabular}{llllll}
\hline $\begin{array}{l}\text { DDW } \\
(\mathrm{ppm})\end{array}$ & $\begin{array}{l}\text { Body weight } \\
(\mathrm{g})\end{array}$ & $\begin{array}{l}\text { Chow } \\
(\mathrm{g} / 100 \mathrm{~g} \text { bw./day })\end{array}$ & $\begin{array}{l}\text { Water consumption } \\
(\mathrm{ml} / 100 \mathrm{~g} \text { bw./day })\end{array}$ & $\begin{array}{l}\text { Diuresis } \\
(\mathrm{ml} / 100 \mathrm{~g} b w . / d a y)\end{array}$ & $\begin{array}{l}\text { Glycoseuria } \\
(\mathrm{mmol} / 100 \mathrm{~g} \text { bw/day })\end{array}$ \\
\hline 150 & $\begin{array}{l}470.0 \pm 32.7 \\
(8)\end{array}$ & $6.2 \pm 0.9$ & $11.8 \pm 1.9$ & $5.3 \pm 1.9$ & $0.31 \pm 0.1$ \\
25 & $\begin{array}{l}449.0 \pm 31.1 \\
(8)\end{array}$ & $5.4 \pm 0.4$ & $10.0 \pm 1.9$ & $5.9 \pm 1.7$ & $0.33 \pm 0.1$ \\
\hline
\end{tabular}

There were no statistically significant differences between the examined parameters

\begin{tabular}{|c|c|c|c|c|c|}
\hline $\begin{array}{l}\text { DDW } \\
(\mathrm{ppm})\end{array}$ & $\begin{array}{l}\text { Body weight } \\
(\mathrm{g})\end{array}$ & $\begin{array}{l}\text { Chow } \\
\text { (g/100 g.bw./day) }\end{array}$ & $\begin{array}{l}\text { Water consumption } \\
\text { (ml/100 g.bw./day) }\end{array}$ & $\begin{array}{l}\text { Diuresis } \\
\text { (ml/100 g.bw./day) }\end{array}$ & $\begin{array}{l}\text { Glycoseuria } \\
\text { (mmol/100 g.bw./day) }\end{array}$ \\
\hline 150 & $\begin{array}{l}243.0^{*} \pm 15.6 \\
(8)\end{array}$ & $26.5^{*} \pm 9.5$ & $156.3^{*} \pm 16.3$ & $102.6^{*} \pm 24.0$ & $120.6^{*} \pm 20.2$ \\
\hline 25 & $\begin{array}{l}255.2^{*} \pm 29.6 \\
(8)\end{array}$ & $24.8^{*} \pm 8.9$ & $165.8^{*} \pm 21.6$ & $105.1^{*} \pm 16.9$ & $118.31^{*} \pm 23.5$ \\
\hline
\end{tabular}

There were no statistically significant differences between the examined parameters

Stars indicate significant differences $(p<0.001)$ compared to the corresponding values of the non-diabetic animals 
Group130 $(n=8) 130$ ppm D, Group135 $(n=8) 135$ ppm D, Group140 $(n=8) 140$ ppm D, Group145 $(n=8) 145$ ppm D and Group150 $(n=8) 150$ ppm deuterium-containing water, respectively. Treatments started at the 2 nd week after STZ injection and lasted for 4 weeks.

Food intake, water consumption, and body weight were measured daily. Blood samples from the tail vein and $24 \mathrm{~h}$ urine samples were collected once a week. Blood samples were taken $4 \mathrm{~h}$ after insulin on $60 \mathrm{mg} / \mathrm{mL}$ EDTA (Sigma, Budapest, Hungary) as anticoagulant. The plasma samples were obtained by centrifugation at $3000 \times g$ for $15 \mathrm{~min}$ at $4{ }^{\circ} \mathrm{C} .24 \mathrm{~h}$ urine samples were collected in tubes containing $200 \mu \mathrm{L}$ of $10 \%$ boronic acid solution to prevent bacterial contamination. After measuring the volume, urine was centrifuged at $3000 \times \mathrm{g}$ for $10 \mathrm{~min}$ and the supernatant was used for analysis. All samples were stored at $-80{ }^{\circ} \mathrm{C}$ until elaboration.

At the end of the study, all animals were placed into metabolic cages individually for $24 \mathrm{~h}$ and exsanguinated under $60 \mathrm{mg} / \mathrm{kg}$ body weight pentobarbital (Nembutal, Abbott Labs, Chicago, IL, USA) anesthesia. After sacrificing the animals, soleus muscle was rapidly excised, washed in physiological saline solution, weighted, frozen in liquid nitrogen, and stored at $-80{ }^{\circ} \mathrm{C}$ until processing.

\section{Plasma glucose}

Plasma Glucose was determined spectrophotometrically using reagent kits from Reanal Finechemical Co. (Budapest, Hungary).

\section{Insulin concentration}

Insulin concentration was determined using an Insulin ELISA kit obtained from Agilent Dako (Santa Clara, CA). The plates were analyzed by a Biorad microplate reader.

\section{Plasma fructosamine concentration}

Plasma fructosamine concentration was determined spectrophotometrically using the micro method developed by Oppel et al. [28], based upon the classical method of Johnson et al. [29], with minor modifications. In brief, fructosamine reagent was prepared by dissolving $50 \mathrm{mg}$ nitroblue tetrazolium (NBT, from Sigma, Budapest, Hungary) in $244.6 \mathrm{~mL}$ carbonate buffer ( $\mathrm{pH}: 10.11)$. Standard was prepared from bovine serum albumin as described previously in detail [23]. Twenty $\mu \mathrm{l}$ of plasma or an adequate volume of standard solution was pipetted into the wells of a 96-well plate in three parallels, respectively. After the addition of $200 \mu \mathrm{l}$ reagent into each well, the plates were profoundly shaken and then incubated at $37{ }^{\circ} \mathrm{C}$ for $10 \mathrm{~min}$. The initial absorbance was read at $490 \mathrm{~nm}\left(\mathrm{~A}_{1}\right)$. Following a subsequent incubation for
$10 \mathrm{~min}$, the absorbance was read again at $490 \mathrm{~nm}\left(A_{2}\right)$. Fructosamine concentration $\left(C_{\text {sample }}\right)$ was calculated from Eq. 1, below $C_{\text {standard }}$ represents the fructosamine concentration of the standard solution:

$\frac{(A 2-A 1) \text { Sample }}{(A 2-A 1) \text { Standard }} \times C_{\text {Standard }}=C_{\text {Sample }}$

\section{Glycosylated hemoglobin (HbA1c)}

Glycosylated hemoglobin (HbA1c) was determined using an affinity chromatography method, previously described by Gould et al. [30]. In brief, $30 \mu \mathrm{l}$ of blood samples (collected without anticoagulants) were hemolysated in $500 \mu \mathrm{L}$ deionised water. Pierce ${ }^{\mathrm{TM}}$ Immobilized Boronic Acid Gel (Thermo Fischer Sci., Waltham, MA) was equilibrated in washing buffer (250 mmol ammonium acetate, $50 \mathrm{mmol}$ magnesium chloride, $3 \mathrm{mmol}$ sodium azide, $\mathrm{pH}=8.5$ ), and poured into columns $(1 \mathrm{~mL})$. After further washing of the columns with washing buffer $(10 \mathrm{~mL}), 100 \mu \mathrm{L}$ of the hemolysate were transferred to the top of the columns and allowed to soak in. Unbound hemoglobins were eluted by passing $8 \mathrm{~mL}$ of washing buffer through the column. Bound (glycosylated) hemoglobin was then eluted with $3 \mathrm{~mL}$ of elution buffer (200 mmol sorbitol, $50 \mathrm{mmol}$ EDTA, $3 \mathrm{mmol}$ sodium azide, $100 \mathrm{mmol}$ Tris, $\mathrm{pH}=8.5$ ). The unbound fraction, containing most of the hemoglobin was diluted to $15 \mathrm{~mL}$ with washing buffer. The absorbance of each fraction was measured at $405 \mathrm{~nm}$ and the amount of hemoglobin bound (glycosylated) was calculated as a percentage of the total.

\section{Isolation of the membrane fraction of soleus muscle}

Isolation of the membrane fraction of soleus muscle was performed according to Villanueva-Peñacarrillo ML et al. [31] supplemented by Lise Coderre et al.-ultracentrifugal separation process [32]. Briefly, soleus muscles from each rat hind limb were removed and trimmed of connective tissue, fat and nerves. One gram of tissue was minced well and homogenized in $10 \mathrm{ml}$ of lysis buffer $(20 \mathrm{mM}$ Tris-HCl, 5 mM EDTA, 10 mM EGTA, 2 mM DTT, $1 \mathrm{mM}$ $\mathrm{Na}_{3} \mathrm{VO}_{4}, 25 \mu \mathrm{g} / \mathrm{mL}$ PMSF, $2.5 \mu \mathrm{g} / \mathrm{mL}$ Leupeptin, $2.5 \mu \mathrm{g} /$ $\mathrm{mL}$ Aprotinin, $625 \mu \mathrm{M}$ sodium-pyrophosphate, $1 \mathrm{mM}$ $\beta$-glycerophosphate, $0,1 \%$ Triton) by a Polytron homogenizer for $3 \times 15 \mathrm{~s}$ on ice. The homogenate was centrifuged at $2500 \times g$ for $10 \mathrm{~min}$ at $4{ }^{\circ} \mathrm{C}$, and the pellet was discarded. The supernatant was then centrifuged at $100000 \times g$ for $60 \mathrm{~min}$ in a Beckman SW55 rotor. The pellet was resuspended in $0.5 \mathrm{~mL}$ lysis buffer containing $38 \%$ sucrose and $1.5 \mathrm{~mL}$ each of 25,30 and $35 \% \mathrm{wt} / \mathrm{wt}$ sucrose solution were layered on the top and centrifuged at $50.000 \times g$ for $16 \mathrm{~h}$. Membrane fraction from the interphase $25 / 30 \%$ was collected, diluted 
with washing buffer (250 mM sucrose, $1 \mathrm{M} \mathrm{NaCl}, 10 \mathrm{mM}$ Tris-HCl, $10 \mathrm{mM}$ EDTA, $3.3 \mu \mathrm{g} / \mathrm{mL}$ PMSF, $1 \mu \mathrm{g} / \mathrm{ml}$ Aprotinin) and recovered by centrifugation at $100,000 \times g$ for $60 \mathrm{~min}$. The pellet was finally resuspended and homogenized in washing buffer, and the total membrane protein content was measured by the Bradford method. Following protein assay, samples were stored at $-80^{\circ} \mathrm{C}$ and used within four weeks for GLUT4 assay. Membranes collected from the interphase 25/30 are considered the plasma membrane fraction, since they show, by convention, enrichment in plasma membrane markers [33].

\section{Western blot analyses}

The samples were prepared in $2 \times$ Laemmli buffer containing $100 \mathrm{mmol}$ dithiothreitol and boiled in a water bath for $15 \mathrm{~min}$. Protein $(50 \mu \mathrm{g})$ was separated on an SDS-PAGE $(10 \%)$ gel followed by a wet transfer to a nitrocellulose membrane for $90 \mathrm{~min}$. Total protein was visualized by Ponceau staining, and GLUT4 blots were normalized to the $45 \mathrm{kDa}$ band. The membranes were blocked for $1 \mathrm{~h}$ at room temperature in $10 \%(\mathrm{wt} / \mathrm{vol})$ nonfat dried milk in Tris-buffered saline (TBS) with $0.1 \%$ Tween 20 (TBST) and then incubated overnight with antibodies against the GLUT4 glucose transporter, purchased from Calbiochem-Sigma (Budapest, Hungary) and diluted (1:3000) in 1\% bovine serum albumin in TBST. Blots were incubated with an HRP-conjugated secondary antibody in TBST for $1 \mathrm{~h}$ at room temperature and visualized by Enhanced Chemiluminescence (ECL) (BioRad, Budapest, Hungary). The ODs of bands were determined by densitometry. All chemicals not mentioned otherwise were purchased from Sigma (Budapest, Hungary).

\section{Statistical analyses}

The results are presented as the mean \pm SEM of $n$ observations. The data were subjected to either one-way repeated measures analysis of variance (ANOVA) or post hoc Student-Newman-Keuls test or were evaluated by Student's $t$ test. Differences of $p<0.05$ were considered significant.

\section{Results}

\section{DDW as drinking water reduced plasma glucose concentration and improved the metabolic parameters in diabetic rats}

To evaluate the effect of DDW on the glucose metabolism in streptozotocin (STZ)-induced diabetic rat model, first we aimed to test the $25 \mathrm{ppm}$ D-concentration, which was the lowest D-concentration of DDW available. In animals without any insulin treatment, DDW alone did not affect blood glucose concentration. However, in animals that received both insulin and DDW, the glucose concentration was lower compared to the animals receiving tap water only, and the difference was significant when a low dose of $(2 \times 1 \mathrm{IU} / 300 \times g$ bw./day) insulin was used (Fig. 1). These results indicate that deuterium depletion, in the presence of insulin, can affect blood glucose levels in diabetic animals.

To evaluate the changes of metabolic parameters in nondiabetic rats receiving drinking water with $150 \mathrm{ppm}$ or $25 \mathrm{ppm}$ D content for four weeks were individually placed in metabolic cages for $24 \mathrm{~h}$ and the amount of fluid and food consumed was measured and the volume of urine excreted and its glucose content were determined.

To evaluate the changes of metabolic parameters in STZtreated diabetic rats receiving drinking water with $150 \mathrm{ppm}$ or $25 \mathrm{ppm} \mathrm{D}$ content for four weeks were individually placed in metabolic cages for $12 \mathrm{~h}$, without insulin administration, and the amount of fluid and food consumption, the volume of urine excretion and its glucose content were measured, respectively.

In conclusion, the $\mathrm{D}$ content of the drinking water did not significantly affect the parameters studied in either non-diabetic or STZ-treated animals without insulin administration.

Next, to determine the most effective D-concentration, DDW with $25,75,105$, and 125 ppm D-concentrations was tested along with the application of a low insulin dose only. Surprisingly, we found that the $125 \mathrm{ppm}$ value, which was closer to the natural D level, was the most effective

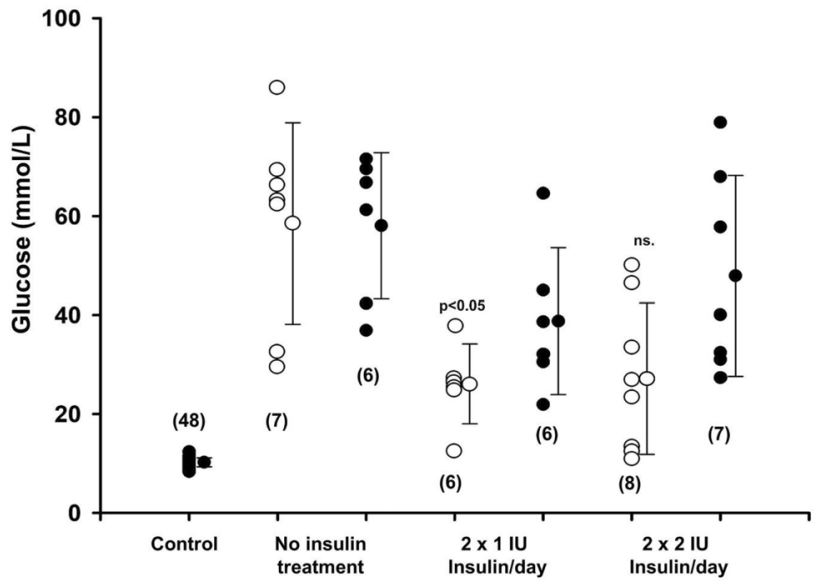

Fig. 1 The effect of DDW (25 ppm) on the serum glucose level of diabetic rats treated with low (twice 1 IU/300 g bw/day) and moderate dose (twice $2 \mathrm{IU} / 300 \mathrm{~g}$ bw/day) of insulin at the end of the fourth week of treatment. Administration of insulin in a low dose significantly $(p<0.05)$ reduced the serum glucose level in DDW-treated animals only. Open and closed circles represent the data obtained from animals receiving either DDW (25 ppm) or tap water, respectively. Numbers in brackets show the number of animals in each group 
D-concentration in reducing blood glucose levels in diabetic animals. (Fig. 2).

The milder decrease of deuterium content of drinking water exerted the greatest effect on serum glucose level. (All data points were significantly $(p<0.01)$ lower compared to the animals receiving tap water). The inset shows the values for the symbols.

To test the dose-dependent effect of deuterium content of drinking water on the metabolic parameters STZ-treated rats receiving various concentrations of DDW as drinking water for four weeks were individually placed in metabolic cages for $12 \mathrm{~h}$, after receiving their insulin injections (1 IU insulin/300 g body weight). The amount of fluid and food consumed was measured, and the volume of urine excreted and its glucose content were determined. (Table 3.)

Table 3. Effect of deuterium content of drinking water on the metabolic parameters of diabetic rats treated with insulin (twice $1 \mathrm{IU} / 300 \mathrm{~g}$ bw/day).

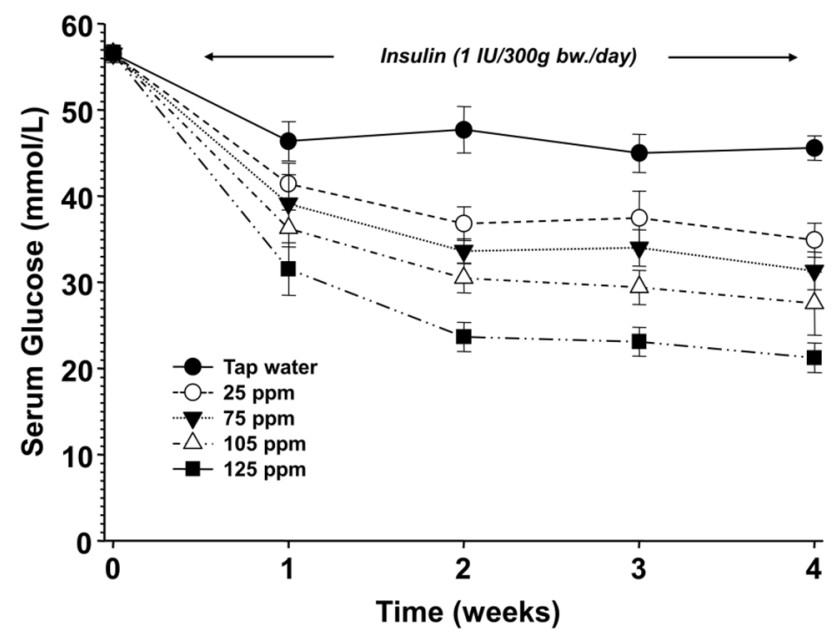

Fig. 2 The effect of deuterium content of drinking water on the serum glucose concentration in diabetic rats treated with insulin (twice $1 \mathrm{IU} / 300 \mathrm{~g}$ bw./day)
All evaluated parameters were significantly different $(p<0.001)$ from the corresponding values of the non-diabetic animals. $+(p<0.05),++(p<0.01)$ are significant differences compared to the corresponding values of the 150-ppm-DDW-receiving animals.

Figures 3-5 show the summary of three experiments in which the following D-concentrations were applied: 25 , $75,105,125,130,135,140,145 \mathrm{ppm}$ and $150 \mathrm{ppm}$ in the control group. Low dose of insulin was used along with all D-concentrations.

The results revealed that the most effective D-concentrations were in the range of $125-140$ ppm (Fig. 3), which was further confirmed by measurements of fructosamine and HbA1c concentrations (Figs. 4, 5).

The inset graphs show the magnified part of the curve between the deuterium content of $125 \mathrm{ppm}$ and $150 \mathrm{ppm}$, respectively. Animals receiving drinking water containing below $140 \mathrm{ppm}$ deuterium had significantly $(* * * p<0.01)$ lower blood glucose levels than those that had access to tap water.

The inset graphs show the magnified part of the curve between the deuterium content of $125 \mathrm{ppm}$ and $150 \mathrm{ppm}$, respectively. Animals receiving less than $145 \mathrm{ppm}$ deuterium-containing drinking water had significantly $(* * * p<0.01)$ lower fructosamine levels than those which had access to tap water. Animals receiving drinking watercontaining $135 \mathrm{ppm}$ deuterium had the lowest fructosamine levels among the DDW-treated animals. Three pluses, $(+++p<0.01)$ versus the value for rats receiving drinking water-containing $25 \mathrm{ppm}$ deuterium.

The inset graphs show the magnified part of the curve in the range of the deuterium content between 125 and $150 \mathrm{ppm}$. Animals receiving drinking water below $140 \mathrm{ppm}$ deuterium content had significantly $(* * * p<0.01)$ lower HbA1c values than those which had access to tap water (150 ppm). Furthermore, symbols indicate the significance level of data compared to animals receiving $25 \mathrm{ppm}$
Table 3 Effect of deuterium content of drinking water on the metabolic parameters of diabetic rats treated with insulin (twice $1 \mathrm{IU} / 300 \mathrm{~g}$ bw./day)

\begin{tabular}{|c|c|c|c|c|c|}
\hline $\begin{array}{l}\text { DDW } \\
(\mathrm{ppm})\end{array}$ & $\begin{array}{l}\text { Body weight } \\
(\mathrm{g})\end{array}$ & $\begin{array}{l}\text { Chow } \\
\text { (g/100 g.bw./day) }\end{array}$ & $\begin{array}{l}\text { Water consumption } \\
\text { (ml/100 g.bw./day) }\end{array}$ & $\begin{array}{l}\text { Diuresis } \\
\text { (ml/100 g.bw./day) }\end{array}$ & $\begin{array}{l}\text { Glycosuria } \\
\text { (mmol/100 g.bw./day) }\end{array}$ \\
\hline 150 & $\begin{array}{l}258.3 \pm 33.3 \\
(8)\end{array}$ & $24.2 \pm 3.43$ & $145.2 \pm 18.2$ & $83.3 \pm 17.5$ & $119.7 \pm 16.8$ \\
\hline 125 & $\begin{array}{l}350.0 \pm 36.7 \\
(8)\end{array}$ & $10.9 \pm 1.4^{++}$ & $42.4 \pm 4.5^{++}$ & $19.3 \pm 2.9^{++}$ & $47.1 \pm 9.8^{++}$ \\
\hline 105 & $\begin{array}{l}323.2 \pm 36.8 \\
(7)\end{array}$ & $16.3 \pm 3.4^{+}$ & $82.1 \pm 16.9^{+}$ & $35.6 \pm 20.6^{+}$ & $63.7 \pm 20.9^{+}$ \\
\hline 75 & $\begin{array}{l}315.1 \pm 24.0 \\
(8)\end{array}$ & $17.4 \pm 2.4$ & $87.8 \pm 19.1$ & $50.7 \pm 16.0$ & $88.5 \pm 26.8$ \\
\hline 25 & $\begin{array}{l}306.4 \pm 34.7 \\
(8)\end{array}$ & $19.2 \pm 2.7$ & $95.9 \pm 22.4$ & $71.0 \pm 21.1$ & $93.6 \pm 16.5$ \\
\hline
\end{tabular}




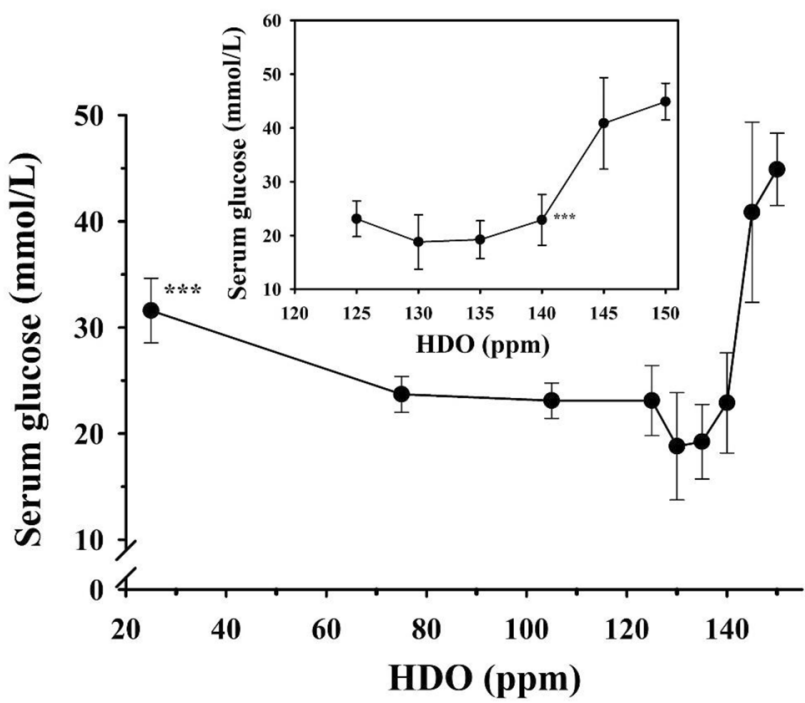

Fig. 3 The effect of deuterium content of drinking water on the blood glucose level in diabetic rats treated with insulin (twice $1 \mathrm{IU} / 300 \mathrm{~g}$ bw/day)

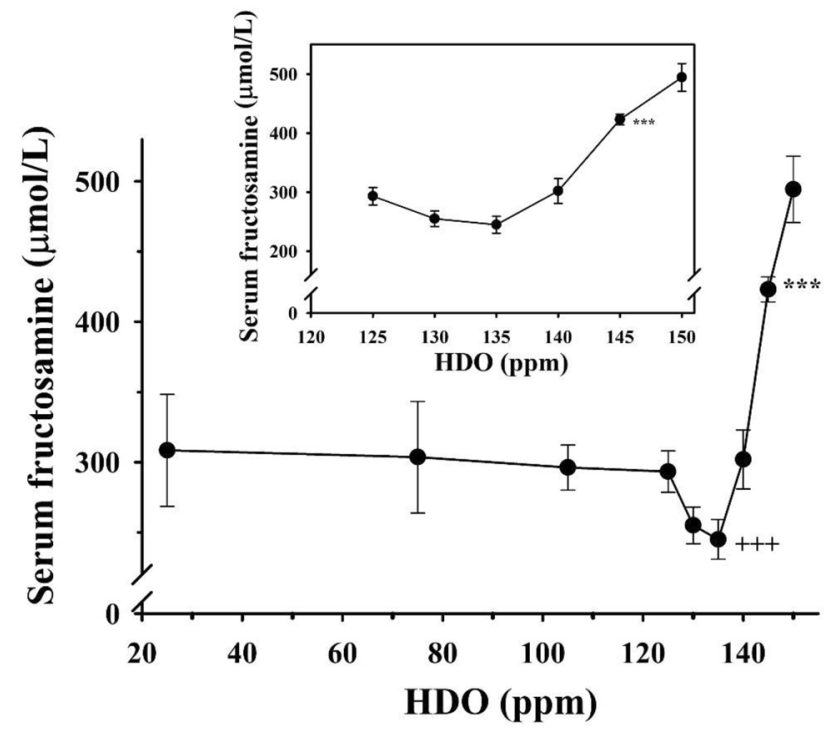

Fig. 4 The effect of deuterium content of drinking water on the fructosamine level in diabetic rats treated with insulin (twice $1 \mathrm{IU} / 300 \mathrm{~g}$ bw/day)

deuterium-containing drinking water. $(+$ meaning $p<0.05$; $++p<0.025 ;+++p<0.01)$.

\section{DDW did not influence the half-life of insulin in blood}

The first experiment revealed that the presence of insulin is essential for DDW to be able to reduce blood glucose concentration. To exclude the possibility that deuterium

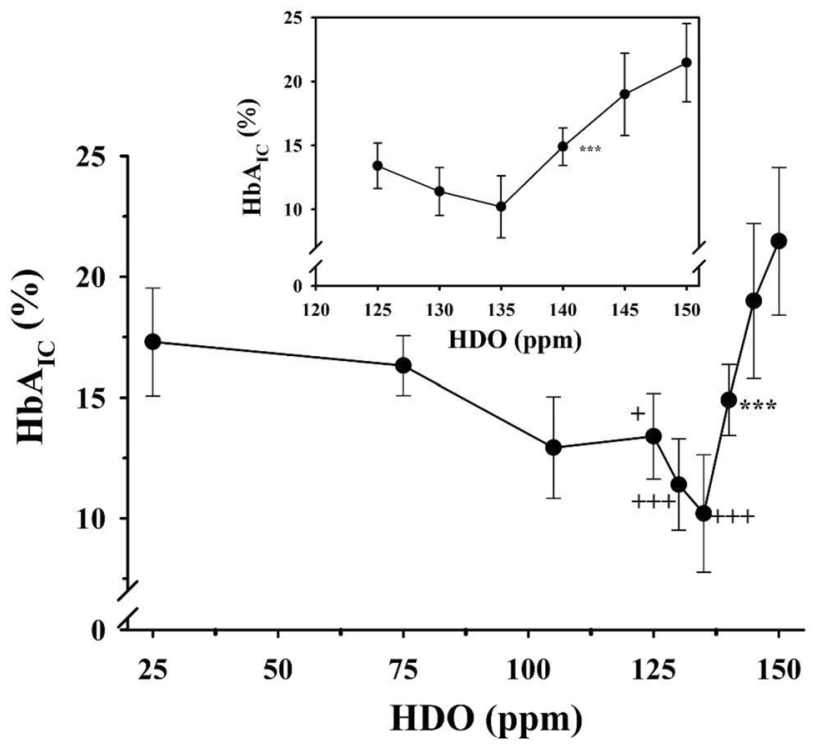

Fig. 5 The effect of deuterium content of drinking water on the $\mathrm{HbA1c}$ level in diabetic rats treated with insulin (twice $1 \mathrm{IU} / 300 \mathrm{~g}$ bw./day)

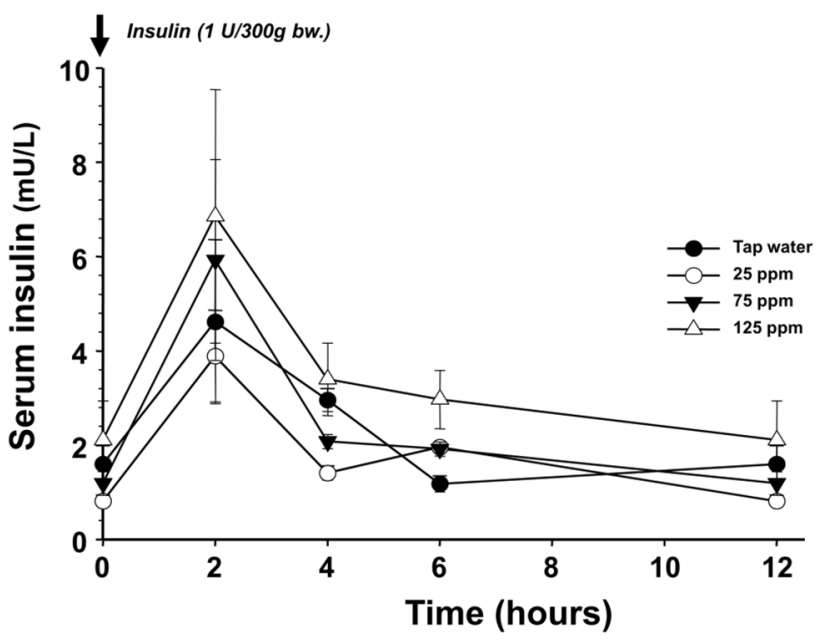

Fig. 6 The elimination of a single dose (1 IU/300 g bw.) of human insulin has not been altered by the concentration of deuterium in the drinking water in STZ-treated rats

depletion may stabilize the insulin in the plasma which results in lower blood glucose levels, the insulin concentration of the blood plasma was determined after the administration of DDW. The insulin concentration was the highest two hours after administration and there was a gradual decrease for $10 \mathrm{~h}$ until the next administration, but the data did not support the hypothesis that DDW influences insulin stability (Fig. 6).

The symbols represent different deuterium contents in the drinking water: tap water (closed circle), $25 \mathrm{ppm}$ (open 
circle), $75 \mathrm{ppm}$ (closed inverted triangle), $125 \mathrm{ppm}$ (open triangle), respectively.

The essential role of insulin in the mechanism influenced by the lowering D-concentration was also confirmed by following the correlation between insulin and glucose concentration after every two hours of administration. The data show that the blood glucose concentration was the lowest two hours after the administration, when the insulin level was the highest. The glucose concentration was $52 \mathrm{mmol} / \mathrm{L}$ in the control group, but $43 \mathrm{mmol} / \mathrm{L}, 36 \mathrm{mmol} / \mathrm{L}$, and $15 \mathrm{mmol} / \mathrm{L}$ in correlation with the D-concentrations of 25 , 75 or 125 ppm, respectively (Fig. 7).

The symbols represent different deuterium contents of the drinking water: tap water (closed circle), $25 \mathrm{ppm}$ (open circle), $75 \mathrm{ppm}$ (closed inverted triangle), $125 \mathrm{ppm}$ (open triangle), respectively. All data points of $125 \mathrm{ppm}$ deuterium are significantly $(p<0.05)$ lower than the values obtained by other treatments.

\section{DDW dose-dependently potentiates the effect of insulin, in part, due to the increased GLUT4 protein translocation from the cytoplasm to the membrane}

As glucose is cleared from the bloodstream by a family of facilitative transporters (GLUTs) and the GLUT4 isoform is the major insulin-responsive transporter, we planned to measure the amount of GLUT4 in the membrane fraction of the soleus muscle. Figure 8 shows that in non-diabetic rats the GLUT4 level was high and remained the same independently of D-concentration in the drinking water (25 ppm or $150 \mathrm{ppm})$

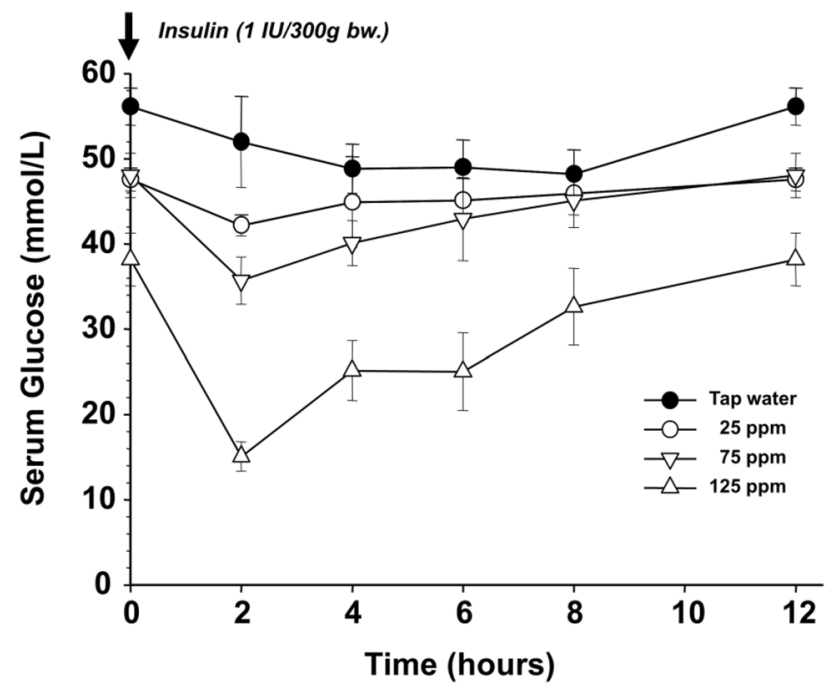

Fig. 7 Changes of serum glucose concentration after the administration of $1 \mathrm{IU} / 300 \mathrm{~g}$ bw. insulin to STZ-treated animals receiving various deuterium concentration categories of drinking water

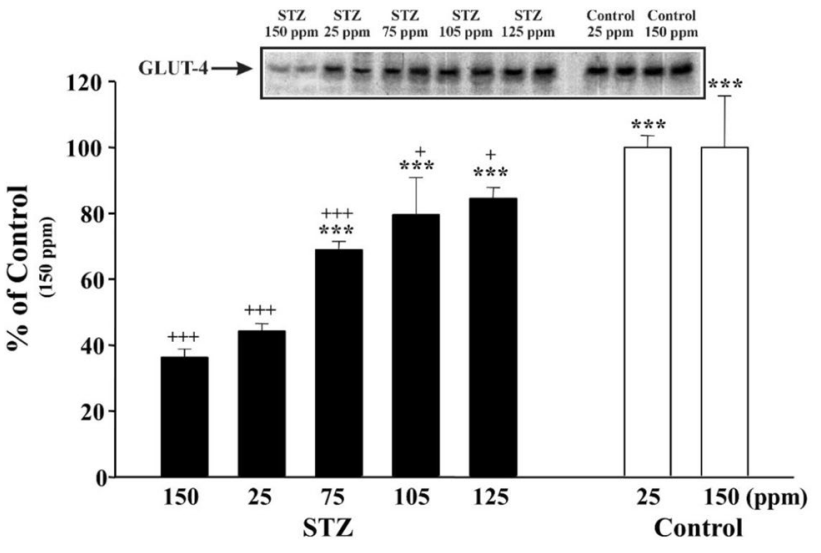

Fig. 8 The effect of the deuterium content of drinking water on insulin-induced translocation of GLUT4 to the membrane in the soleus muscle

For the experimental protocol, see the Materials section. Inset shows a representative immunoblot of insulinpromoted GLUT4 translocation to the membrane fraction. Bars indicate the mean values of the densitometry evaluation of the GLUT4 protein corresponding spots on the immunoblots and expressed as a percentage of the value of the tap water given to control group (non-diabetic) animals. Three asterisks indicate $p<0.01$ versus STZ-treated and tap-waterreceiving animals. Three pluses indicate $p<0.01$, one plus $p<0.05$, versus control, non-diabetic animals.

In diabetic rats, we found a strong correlation between the amount of GLUT4 in the membrane fraction and the blood glucose concentration. As the blood glucose concentration was the highest in the control group, the lowest GLUT4 level was detected in the membrane, but at the same time the $125 \mathrm{ppm}$ DDW resulted in the lowest glucose concentration. This can be explained with the highest GLUT4 level being in the membrane.

\section{Discussion}

There has been increasing evidence that naturally occurring deuterium has a central role in living organisms since the first paper was published [9]. In the early 90s, research primarily focused on the anticancer effect of DDW [9-19], but for today it is clear that D and more probably the changing $\mathrm{D} / \mathrm{H}$ ratio has an exceptional role in the regulation of biochemical-, genetic- and physiological processes [13, 25, 34, 35]. In this study, we proved that the changes in D-concentrations in water may potentiate the insulin-regulated membrane trafficking by recruiting membrane vesicles containing the GLUT4 glucose transporters from the interior of cells to the cell surface. One of the most striking results was that it was not the lowest 
D-concentration $(25 \mathrm{ppm})$ that exerted the most significant stimulus on the insulin signal transduction system, but a narrow subnatural concentration range between 125 and $140 \mathrm{ppm}$. These findings suggest that the results cannot be attributed only to the kinetic isotope effect, because in this case the lowest D-concentration would exert the strongest effect, and the hitherto unknown submolecular regulatory system is very sensitive to changes in the $\mathrm{D} / \mathrm{H}$ ratio in this range. Previous work [9] suggested that a $\mathrm{Na}^{+} / \mathrm{H}^{+}$antiport activation may lead to an increased D/H ratio because the transport system prefers to eliminate the lighter isotope $\left(\mathrm{H}^{+}\right)$, which may serve as a key signal to promote cell proliferation [9]. Recent results suggest that properly working mitochondria can keep the $\mathrm{D} / \mathrm{H}$ ratio at a lower level, because lipid oxidation provides deuteriumdepleted metabolic water [17-19]. We also suggest that the D-concentration varies in the different nutrients depending on the place of cultivation, country of origin, the biochemical pathways for photosynthetic $\mathrm{CO}_{2}$-fixation in plants $[36,37]$, and the ratio of the main organic compounds (carbohydrates, proteins, lipids) also influences cellular processes and has a major impact on metabolism.

Based on our experimental data, deuterium-depleted water can offer clinical benefits in the treatment of patients with metabolic syndrome by increasing insulin sensitivity. The results presented here serve as novel evidence that the naturally occurring deuterium has an important role in living organisms.

Further research is needed to explore whether a similar mechanism could be responsible for the beneficial effect of DDW on the parameters of glucose metabolism in human subjects, however this is beyond the scope of the current study. Nevertheless, deuterium depletion can potentially offer an effective and innocuous tool for treating not only malignant but also metabolic diseases.

Acknowledgements The authors thank all participants for their work and help with this study.

Author contributions Conceptualization, MM, GS; methodology, MM, $\mathrm{KH}, \mathrm{TD}$; software, KH, TD, IS, BZsK.; investigation, MM, KH, TD; resources, GS, IS, BZsK; data curation, KH, TD, IS; writing-original draft preparation, KH, TD, BZsK, IS.; writing-review and editing, $\mathrm{MM}, \mathrm{GS}$; visualization, MM, KH, TD; funding acquisition, GS.

Funding Open access funding provided by Semmelweis University. This work was supported by HYD LLC for Cancer Research and Drug Development.

Data availability All data generated or analysed during this study are included in this published article.

\section{Declarations}

Conflict of interest The authors declare that they have no conflicts of interests.

Ethical approval The animal treatments were in compliance with the guidelines established by the Animal Care Committee of Semmelweis University and the Hungarian Guide for the Care and Use of Laboratory Animals.

Open Access This article is licensed under a Creative Commons Attribution 4.0 International License, which permits use, sharing, adaptation, distribution and reproduction in any medium or format, as long as you give appropriate credit to the original author(s) and the source, provide a link to the Creative Commons licence, and indicate if changes were made. The images or other third party material in this article are included in the article's Creative Commons licence, unless indicated otherwise in a credit line to the material. If material is not included in the article's Creative Commons licence and your intended use is not permitted by statutory regulation or exceeds the permitted use, you will need to obtain permission directly from the copyright holder. To view a copy of this licence, visit http://creativecommons.org/licenses/by/4.0/.

\section{References}

1. Jancsó G (2003) Isotope effects. In: Vértes A, Nagy S, Klencsár Z (eds) Handbook of nuclear chemistry. Kluwer Academic Publishers, Dordrecht, pp 85-116

2. Katz JJ, Crespi HL (1971) Isotope effects in biological systems. In: Collins CJ, Bowman NS (eds) Isotope effects in chemical reactions. Van Nostrand Reinhold, New York, pp 286-363

3. Wiberg KB (1955) The deuterium isotope effect. Chem Rev 55(4):713-743. https://doi.org/10.1021/cr50004a004

4. Czajka DM, Finkel AJ, Fischer CS, Katz JJ (1961) Physiological effects of deuterium on dogs. Am J Physiol 201:357-362

5. Katz JJ, Crespi HL, Czajka DM, Finkel AJ (1962) Course of deuteriation and some physiological effects of deuterium in mice. Am J Physiol 203:907-913

6. Yurtsever Y, Gat JR (1981) Stable isotope hydrology. In: Gonfiantini R (ed) Gat JR. International Atomic Energy Agency, Vienna, pp 103-142

7. Craig H (1961) Isotopic Variations in Meteoric Waters. Science 133:1702-1703

8. Rundel PW, Ehleringer JR, Nagy KA (1988) Stable Isotopes. In: Smith J (ed) Ecological Research. Springer, New York

9. Somlyai G, Jancsó G, Jákli G, Vass K, Barna B, Lakics V, Gaál T (1993) Naturally occurring deuterium is essential for the normal growth rate of cells. FEBS Lett 317:1-4

10. Somlyai G, Laskay G, Berkényi T, Galbács Z, Galbács G, Kiss SA, Gy J, Jancsó G (1998) The biological effects of deuteriumdepleted water, a possible new tool in cancer therapy. J Oncol 30:91-94

11. Somlyai G, Laskay G, Berkényi T, Gy J, Jancsó G (1998) Naturally occurring deuterium may have a central role in cell signaling. In: Heys JR, Melillo D (eds) Synthesis and applications of isotopically labelled compounds. Wiley, New York, pp 137-141

12. Cong F, Zhang Y, Sheng H, Ao Z, Zhang S, Wang J (2010) Deuterium-depleted water inhibits human lung carcinoma cell growth by apoptosis. Exp Therapeutic Med 1:277-283

13. Gyöngyi Z, Somlyai G (2000) Deuterium depletion can decrease the expression of C-myc Ha-ras and p53 gene in carcinogentreated mice. Vivo 14:437-440 
14. Kovács A, Guller I, Krempels K, Somlyai I, Jánosi I, Gyöngyi Z, Szabó I, Ember I, Somlyai G (2011) Deuterium depletion may delay the progression of prostate cancer. J Cancer Ther 2:548-556

15. Krempels K, Somlyai I, Gyöngyi Z, Ember I, Balog K, Abonyi O, Somlyai G (2013) A retrospective study of survival in breast cancer patients undergoing deuterium depletion in addition to conventional therapies. J Cancer Res Ther 1(8):194-200

16. Gyöngyi Z, Budán F, Szabó I, Ember I, Kiss I, Krempels K, Somlyai I, Somlyai G (2013) Deuterium depleted water effects on survival of lung cancer patients and expression of Kras, Bcl2 and Myc genes in mouse lung. Nutr Cancer 65(2):240-246

17. Boros LG, Meuillet EJ, Somlyai I, Jancsó G, Jákli G, Krempels K, Puskás LG, Nagy L, Molnár M, Laderoute KR, Thompson PA, Somlyai G (2014) Fumarate hydratase and deuterium depletion control oncogenesis via NADPH-dependent reductive synthesis. AACR 2014 - Annual Meeting, April 5-9, San Diego, CA, USA. https//doi.org/https://doi.org/10.12918/HYD2014AACRPOST

18. Boros LG, D'Agostino DP, Katz HE, Roth JP, Meuillet EJ, Somlyai G (2016) Submolecular regulation of cell transformation by deuterium depleting water exchange reactions in the tricarboxylic acid substrate cycle. Med Hypothes. https://doi.org/10.1016/j. mehy.2015.11.016

19. Boros LG, Somlyai G (2014) Compartmentalized NADPH synthesis, intramolecular deuterium disequilibrium and water pools of mammalian cells. Mol Cell 55:253

20. Malaisse-Lagae F, Greider MH, Malaisse WJ, Lacy PE (1971) The stimulus-secretion coupling of glucose-induced insulin release. $\mathrm{J}$ Cell Biol 49:530-535

21. Beckmann J, Holze S (1980) Inhibitory effect of deuterium oxide on glucose oxidation by pancreatic islet cells. Mol Cell Endocrinol 20:227-231

22. Ashby JP, Shirling D (1981) The priming effect of glucose on insulin secretion from isolated islets of Langerhans. Diabetologia 21:230-234

23. Gunawardana SC, Sharp GW (2002) Intracellular pH plays a critical role in glucose-induced time-dependent potentiation of insulin release in rat islets. Diabetes 51(1):105-113

24. Young LH, Renfu Y, Russell R, Hu X, Caplan M, Ren J, Shulman GI, Sinusas AJ (1997) Low-flow ischemia leads to translocation of canine heart Glut-4 and Glut-1 glucose transporters to the sarcolemma in vivo. Circulation 95:415-422

25. Somlyai G, Somlyai I, Fórizs I, Czuppon GY, Papp A, Molnár M (2020) Effect of systemic subnormal deuterium level on metabolic syndrome related and other blood parameters in humans: a preliminary study. Molecules 25:1376. https://doi.org/10.3390/molec ules25061376

26. Deeds MC, Anderson JM, Armstrong AS, Gastineau DA, Hiddinga HJ, Jahangir A, Eberhardt NL, Kudva YC (2011) Single dose steptozotocin induced diabetes: considerations for study design in islet transplantation models. Lab Anim 45(3):131-140. https://doi.org/10.1258/la.2010.010090
27. Graham ML, Janecek JL, Kittredge JA, Hering BJ, Schuurman H (2011) The Streptozotocin-induced diabetic nude mouse model: differences between animals from different sources. Comp Med 61(4):356-360

28. Oppel K, Kulcsár M, Bárdos L, Ferencz A, Lakner H, Simon J, Temesváry K, Karchesz K (2000) A new, modern, cost-saving micro/macro method for the determination of serum fructosamine. Acta Vet Hung 48(3):285-291

29. Johnson RN, Metcalf PA, Baker JR (1983) Fructosamine: a new approach to the estimation of serum glycosylprotein I. Ind Diabet Control Clin Chim Acta 127:87-95

30. Gould BJ, Hall PM, Cook JG (1982) Measurement of glycosylated haemoglobins using an affinity chromatography method. Clin Chim Acta 125(1):41-48

31. Villanueva-Peñacarrillo ML, Puente J, Redondo A, Clemente F, Valverde I (2001) Effect of GLP-1 treatment on GLUT2 and GLUT4 expression in type 1 and type 2 ratdiabetic models. Endocrine 15:241-248. https://doi.org/10.1385/ENDO:15:2:241

32. Coderre L, Kandror KV, Vallega G, Pilch PF (1995) Identification and characterization of an exercise-sensitive pool of glucose transporters in skeletal muscle. J Biol Chem 270(46):27584-27588. https://doi.org/10.1074/jbc.270.46.27584

33. Klip A, Ramlal T, Young DA, Holloszy JO (1987) Insulin-induced translocation of glucose transporters in rat hindlimb muscles. FEBS Lett 224:224-230. https://doi.org/10.1016/0014-5793(87) 80452-0

34. Mladin C, Ciobica A, Lefter E, Popescu A, Bild W (2014) Deuterium-depleted water has stimulating effects on long-term memory in rats. Neurosci Lett 583:154-158. https://doi.org/10.1016/j.neulet.2014.09.037

35. Zhang X, Gaetani M, Chernobrovkin A, Zubarev RA (2019) Anticancer effect of deuterium depleted water-redox disbalance leads to oxidative stress. Mol Cell Proteom 18(12):2373-2387. https:// doi.org/10.1074/mcp.RA119.001455

36. Sternberg OL, Deniro JM, Johnson BH (1984) Isotope ratios of cellulose from plants having different photosynthetic pathways. Plant Physiol 74:557-561

37. Youping Z, Benli Z, Hilary SW, Kliti G, Charles HH, Arthur G, Zachary EK, Graham DF (2017) On the contributions of photorespiration and compartmentation to the contrasting intramolecular $2 \mathrm{H}$ profiles of $\mathrm{C} 3$ and $\mathrm{C} 4$ plants sugar. Phytochemistry 145:197-206

Publisher's Note Springer Nature remains neutral with regard to jurisdictional claims in published maps and institutional affiliations. 